\title{
Anatomia do Legender: examinando a tradução colaborativa em Grey's Anatomy
}

\section{The Legender's Anatomy: examining collaborative translation in Grey's Anatomy}

\author{
Erika Nogueira de Andrade Stupielllo*
}

Bruno Fernandes Bertoni ${ }^{* *}$

\begin{abstract}
The purpose of this work is to examine the main attributes that compose the current voluntary subtitling practice by investigating the changes applied to their work in the last years as a result of the developments in the information technology area. The analysis was carried out based on the investigation of the accuracy and suitability of the translations of technical terms by the voluntary subtitling team InSUBs, one of the most renowned in the Brazilian community, to the American medical TV drama Grey's Anatomy. The voluntary subtitles were compared to the professional ones, and the results suggest that the practice can no longer be deemed amateur, but can be currently seen as firmly grounded on training, research and setting of technical standards.
\end{abstract}

Keywords: Audiovisual translation; voluntary subtitling; legender; fansub; Grey's Anatomy; InSUBs.

Resumo: 0 objetivo deste trabalho é examinar as características principais que constituem o trabalho de legendagem voluntária atual pela investigação das mudanças implementadas nessa prática nos últimos anos em função dos desenvolvimentos das tecnologias de informação. A análise foi realizada com base na investigação da precisão dos termos técnicos traduzidos pelos membros da equipe de legendagem voluntária InSUBs, uma das mais renomadas da comunidade, para o drama médico americano Grey's Anatomy. As legendas voluntárias foram comparadas

"Professora de Tradução do Departamento de Letras Modernas da Unesp de São José do Rio Preto. Pesquisadora em Estudos da Tradução. Tradutora pública e intérprete comercial. Email: erika@ibilce.unesp.br

"Graduando em Letras com Habilitação de Tradutor. E-mail: bfbertoni2@gmail.com

TradTerm, São Paulo, v. 33, maio/2019, p. 26-53 www.revistas.usp.br/tradterm 
às profissionais, e os resultados indicam que a prática deixou de ser amadora há algum tempo, podendo ser vista atualmente como um trabalho voluntário com respaldo em treinamentos, pesquisa e estabelecimento de normas técnicas.

Palavras-chave: Tradução audiovisual; legenda voluntária; legender; fansub; Grey’s Anatomy; InSUBs.

\section{Introdução}

A conexão pública à internet, autorizada no Brasil em novembro de 1995, revolucionou as estruturas sociais que conhecíamos até o final do milênio passado: a world-wide web transformou a forma como nos comunicamos, trabalhamos, ganhamos e gastamos nosso dinheiro, produzimos conteúdo, inteligência, entretenimento e cultura. Pode-se dizer que o mundo todo transformou-se em um grande "aqui", que gira ao redor de um consensual "agora". De acordo com o Internet Live Stats ${ }^{1}$, que mede estatísticas de tráfego em tempo real, há 3,9 bilhões de pessoas conectadas à rede neste momento; mais de um trilhão de buscas foram realizadas no Google só no primeiro semestre de 2018, mesmo período em que 1,1 trilhão de vídeos foram assistidos no YouTube - a título de curiosidade, o número

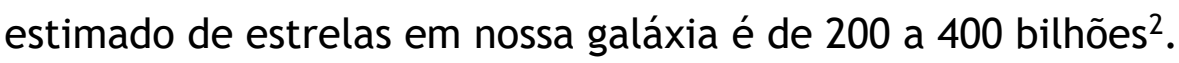

Esses números sustentam o fato de que nunca, na história de nossa espécie, se produziu e se compartilhou tanto conteúdo. É uma mudança assombrosa para uma sociedade que, até então, consumia mais conteúdo do que produzia: não era tão simples conquistar um lugar de fala em uma emissora de televisão ou publicar um artigo de opinião em um jornal quanto é, nos dias de hoje, criar uma conta no Facebook e divulgar praticamente todo tipo de conteúdo no YouTube. Como explica Jenkins (2006):

Essa circulação de conteúdo - entre diferentes sistemas de mídia, economias midiáticas concorrentes e fronteiras nacionais - depende vigorosamente da participação ativa dos consumidores. Sou contra a ideia de que a convergência deve ser entendida primariamente como um processo tecnológico de interação entre mecanismos midiáticos múltiplos dentro de um mesmo dispositivo. Na realidade, a convergência representa uma mudança cultural

\footnotetext{
${ }^{1}$ Disponível em: <http://www.internetlivestats.com>. Acesso em 29 jun. 2018.

${ }^{2}$ Disponível em: <http://www.inpe.br/acessoainformacao/node/450>. Acesso em 29 jun. 2018.
} 
em que consumidores são incentivados a procurar novas informações e criar conexões entre conteúdos disseminados. (JENKINS 2006: 3)

A internet abriu fronteiras culturais maiores do que a mídia tradicional jamais conseguiu: embora muitas emissoras de TV aberta ou fechada transmitam séries e filmes estrangeiros, esses produtos são mais acessíveis online e possuem uma disponibilidade praticamente imediata ao seu lançamento, independentemente da localidade de quem o procura. Isso significou, para a indústria do entretenimento, uma expansão muito grande: as séries estrangeiras se popularizaram de forma exponencial no Brasil e reuniram fãs assíduos e criativos. De acordo com Spolidorio (2017),

É essa mistura de adoração, admiração, entusiasmo e fascinação pelo produto cultural que faz com que os fãs se reúnam para conversar, discutir e celebrar juntos, mas é a frustração, a insatisfação e o inconformismo em aceitar que o que está disponível é finito e representa o tudo que existe e tudo o que há para se saber sobre tópico em questão que faz com que os fãs interajam ativamente criando novos materiais para divulgar, propagar e perpetuar 0 conteúdo disponível. (SPOLIDORIO 2017: 54)

Nesse contexto, em que fãs se dedicam a interagir com seus produtos favoritos, o papel da tradução é inevitável: embora os episódios de séries sejam disponibilizados on-line poucas horas depois do lançamento oficial, eles não estão traduzidos. Para resolver esse problema, os próprios fãs passaram a traduzir os episódios e a disponibilizar as legendas de forma gratuita on-line. Essa prática, conhecida como fansubbing, não é fruto da internet: fãs de animes japoneses já produziam legendas em VHS para outros consumidores desde 1980 (Bernardo 2011: 12). No entanto, a Web facilitou a produção dessas legendas e promoveu um acesso muito mais amplo tanto aos episódios quanto às suas traduções. Se, outrora, a distribuição de fitas VHS traduzidas dispendia custos para quem as produzia (e, consequentemente, para quem as encomendava), as legendas hoje são realizadas sem um custo específico e disponibilizadas de maneira gratuita. Os fansubbers, como eram conhecidos os legendistas voluntários no início da prática, hoje são conhecidos no Brasil como legenders e, como explica Bernardo (2011):

Eles fazem esse trabalho de graça, ou assim eu imaginei, pois nunca paguei por uma legenda. Entregam as legendas num prazo bem menor do que os meios tradicionais e, muitas vezes, possuem uma qualidade superior ao das 
legendas profissionais. Isso tudo porque o trabalho de legendagem é feito por pessoas que amam os filmes e seriados que legendam. Eles conhecem a obra melhor que qualquer um e prezam pela qualidade antes de qualquer coisa. (BERNARDO 2011: 16).

Os legenders se organizam em equipes e concorrem pela visibilidade nos portais aos quais submetem seus trabalhos: no Brasil, o site mais popular do gênero é o Legendas.TV. É nele que a equipe InSUBs participa desde o início, disponibilizando suas legendas e recebendo apoio e feedback dos usuários. O presente trabalho investiga essa interação entre fãs, produto e consumidores ativos em um contexto de coparticipação criativa on-line.

A equipe que tomaremos como base para nosso estudo da trajetória da prática legender no Brasil é a InSUBs: fundada em 2007 por cerca de trinta fansubbers, hoje ela é composta por quase 460 membros $^{3}$ responsáveis por traduzir, sincronizar, revisar, avaliar e distribuir legendas de 69 séries ${ }^{4}$ estrangeiras. Uma delas é o carro-chefe do sucesso da equipe: Grey's Anatomy. O drama médico reúne fãs em todo o mundo desde março de 2005, tendo sido recentemente confirmada para sua décima quinta temporada - são mais de treze anos no ar e mais de 50 prêmios, incluindo Golden Globes, Primetime Emmys, People's Choice Awards e outros ${ }^{5}$.

Todo esse sucesso reuniu fãs brasileiros que, embora possam assistir às temporadas pelo Canal Sony ou pela Netflix, optam por baixar os episódios na internet: enquanto a Netflix disponibiliza a série com o atraso de uma temporada e o Canal Sony com uma média de 15 episódios anteriores, os capítulos podem ser encontrados na internet poucas horas depois de terem sido transmitidos pela $A B C$, emissora norte-americana de origem do programa.

Os ansiosos fãs brasileiros recorrem à InSUBs, que traduz a série com exclusividade no Legendas.TV, para assistir ao episódio mais recente. Uma vez que Grey's Anatomy se passa em um hospital e narra a história de médicos cirurgiões, o programa é repleto de terminologia médica, detalhes sobre procedimentos cirúrgicos e referências a doenças, equipamentos e órgãos do

\footnotetext{
${ }^{3}$ Disponível em: <http://insubs.com/equipe>. Acesso em 29 jun. 2018.

${ }^{4}$ Disponível em: <http://insubs.com/series>. Acesso em 29 jun. 2018.

${ }^{5}$ Disponível em: <https://www.imdb.com/title/tt0413573/awards>. Acesso em 29 jun. 2018.
} 
corpo humano. A tradução desses elementos, bastante desafiadora para tradutores não profissionais, constitui um intrigante campo de pesquisa sobre a prática de tradução colaborativa, ajudando-nos a compreender o nível de organização da pesquisa técnica e terminológica adotada pelos legenders, entender as diferenças e semelhanças entre a prática voluntária e a profissional e, ainda, indicar métodos de trabalho colaborativo que possam ser aplicados à formação do tradutor no contexto acadêmico.

Este trabalho apresenta um exame da prática de tradução colaborativa, por meio da análise da evolução do trabalho de legendagem na série Grey's Anatomy. A pesquisa ${ }^{6}$ também contou com entrevistas conduzidas com legenders, usuários finais das legendas e tradutores profissionais. Seus depoimentos serviram de suporte para a análise da articulação do trabalho em equipe e das estratégias de tradução empregadas com vistas a possíveis aplicações no contexto acadêmico de formação de tradutores.

0 primeiro item examina os aspectos estruturais da InSUBs - sua formação e estrutura atual - contextualizando o desenvolvimento da equipe em função dos avanços tecnológicos e de seus impactos socioeconômicos. Já o item seguinte investiga o trabalho realizado pelos legenders da InSUBs em Grey's Anatomy, discutindo as mudanças na prática ao longo do desenvolvimento da equipe. A terceira parte do trabalho discute a opinião de legenders, usuários e tradutores profissionais acerca das legendas produzidas pela InSUBs por meio de um teste, cujos resultados nos permitem compreender quão próxima a legenda voluntária está da profissional. 0 artigo conclui com uma reflexão sobre as possíveis aplicações das estratégias da legenda voluntária ao treinamento de tradutores em formação.

\section{Articulável Mundo Novo: as estruturas da inteligência coletiva na Web.}

\footnotetext{
${ }^{6}$ Projeto de Iniciação Científica com financiamento Fapesp (processo no 2017/05883-9).
} 
O ano de 2007 foi um dos mais marcantes na evolução da internet e da tecnologia como um todo: a Apple lançou seu primeiro iPhone nesse ano, dando início à era dos smartphones; a Microsoft lançou o Windows Vista; o Google disponibilizou o revolucionário serviço Street View e o belíssimo Google Sky, e os usuários brasileiros do YouTube foram presenteados com a primeira versão em língua portuguesa do site. A internet atingiu, no Brasil, uma taxa de $50 \%$ dos usuários conectados à banda larga, o que favoreceu o aumento do número de downloads de arquivos em boa qualidade. Nesse novo cenário, a propriedade dos materiais em circulação ficou muito mais vulnerável, uma vez que,

com o surgimento da internet banda-larga e conexões de alta velocidade, a criação do Youtube (2005) abriu possibilidades para o mundo dos vídeos virais, dos tutoriais, performances artísticas, jornalismo cidadão, entre muitas outras coisas. A invenção dos smartphones (2007) e dos tablets (2010) também influenciou imensamente a maneira como as pessoas usavam as novas mídias e a internet. Os estudos acadêmicos voltaram-se para os desafios em lidar com a existência cada vez mais conectada, a problemática da propriedade intelectual e dos direitos autorais no mundo digital, além de alertar para o controle e a censura por parte de instituições e governos que passaram a ter acesso a dados pessoais presentes no ciberespaço. (DELWICHE, HENDERSON 2013 apud SPOLIDORIO 2017: 60).

De fato, um dos maiores problemas enfrentados pela indústria do entretenimento depois do surgimento e da popularização da Web concernem às questões de propriedade intelectual. Há muita controvérsia, em um universo de dados compartilhados, sobre o que é de quem. Se tomarmos os populares “memes" como exemplo, essa ideia se torna mais clara. Os memes são imagens ou vídeos compartilhados em redes sociais com o objetivo de expressar, por meio de cenas famosas de filmes ou programas de TV, situações comuns do mundo contemporâneo com humor e irreverência. Um dos memes mais famosos no Brasil (e, agora, no mundo ${ }^{7}$ ) é o da personagem Nazaré Tedesco, da novela Senhora do Destino (Rede Globo, 2004), com uma expressão confusa sob cálculos matemáticos; a imagem é utilizada para expressar alguém tentando compreender problemas ou afirmações complexas. $\mathrm{Na}$ última semana de junho de 2018, a Rede Globo decidiu proibir o uso de

\footnotetext{
${ }^{7}$ Disponível em: < https://vejasp.abril.com.br/blog/pop/gringos-descobrem-nazare-tedesco-e-atransformam-em-meme-internacional/>. Acesso em 29 jun. 2018.
} 
imagens de seus programas no Twitter, alegando violação de direitos autorais ${ }^{8}$.

O meme da Nazaré Confusa e a proibição do mesmo pela emissora ilustram a grande batalha entre as produtoras de conteúdo e os internautas: muitos produtos audiovisuais como séries, novelas e filmes, se transformam em assunto e material nas redes sociais; suas cenas são reproduzidas e compartilhadas de diferentes formas - memes, artes de fãs, montagens com músicas, etc. - pelas redes sociais e alcançam públicos inimagináveis. Como explica Jenkins,

o termo "cultura participativa" contrasta com noções antigas de audiência passiva. Em vez de falarmos sobre produtores de mídia e consumidores ocupando papéis separados, devemos vê-los agora como participantes que interagem entre si de acordo com um novo conjunto de regras que nenhum de nós entende completamente. (JENKINS 2006: 3)

Esse conjunto de regras parece basear-se na lógica de que a internet é um grande acervo de material e de que todos que têm acesso a ela são, de certa forma, detentores desse conteúdo. Assim, se um programa é exibido em um local e os computadores atuais possuem equipamentos que permitem a gravação desse produto em alta qualidade, bem como seu compartilhamento em rede mundial, é improvável que entre quase 4 bilhões de pessoas conectadas (mais da metade da população do planeta) ninguém o fará, principalmente quando existe uma grande demanda de consumidores interessados no produto.

À parte os fatores legais associados à prática - distribuir conteúdo protegido por direitos autorais é crime em todos os países -, muitos produtores e estudiosos desse fenômeno têm argumentado que a distribuição de episódios de séries on-line é, na realidade, favorável à popularidade do programa. O diretor de programação da HBO, Michael Lombardo, caracteriza a pirataria do seriado de séries como Game of Thrones (2011) como "um elogio" que corrobora a demanda pela série e seus produtos. Segundo ele, “a

\footnotetext{
${ }^{8}$ Disponível em: < http://gente.ig.com.br/tvenovela/2018-06-21/globo-proibicao-imagenstwitter.html>. Acesso em 29 jun. 2018.
} 
pirataria é algo que acompanha um seriado de grande sucesso em um canal por assinatura"

De fato, a "democratização" proporcionada pela internet trouxe no bojo um novo conjunto de regras e consequências que demanda tempo e recursos para ser assimilado e organizado tanto pela indústria quanto pelos consumidores. Em um mundo virtual e sem fronteiras físicas, dificilmente podemos traçar pontos exatos de propriedade privada, e isso estimula que esses conteúdos sejam compartilhados com frequência e velocidade cada vez maiores.

Essa distribuição de conteúdo levou tradutores do mundo todo a dispenderem tempo e esforços para confeccionar legendas de suas séries e filmes favoritos. Sites como o OpenSubtitles. org $^{10}$ recebem e disponibilizam legendas gratuitas em todos os idiomas especificamente para arquivos de vídeo compartilhados na rede. Ainda em operação, o portal permite que qualquer pessoa cadastrada envie legendas, independentemente da procedência e da qualidade do arquivo.

No Brasil, o site Só Séries funcionou de forma semelhante até 2007. Segundo PenelopeC, veterana administradora da InSUBs, o portal se comportava como um repositório de legendas amadoras em que qualquer pessoa cadastrada podia disponibilizar suas legendas, livre de revisões técnicas para aprovação. Assim, pouco tempo depois que um episódio entrava para o acervo da Web, surgiam diversas traduções para ele. A avaliação da qualidade das legendas cabia exclusivamente ao usuário final, o que tornava grandes as chances de se encontrar uma tradução automática ou malfeita.

Em 2007, a fim de organizar seu conteúdo, o Só Séries passou a atribuir a tradução de determinados programas a grupos específicos de legenders, estimulando a formação de equipes. Alguns dos tradutores mais assíduos e valorizados pelo site formaram a InSUBs, que traduzia séries como Grey's

\footnotetext{
${ }^{9}$ Disponível em: <http://g1.globo.com/tecnologia/noticia/2013/04/game-thrones-quebra-recorde-depirataria-simultanea-nobittorrent.html>. Acesso em 29 jun. 2018

${ }^{10}$ Disponível em: < https://www.opensubtitles.org/pt>. Acesso em 29 jun. 2018.
} 
Anatomy e o Só Séries passou a se chamar Legendas.TV, como é conhecido até hoje.

Os legenders agora se submetiam a algumas regras para publicação de legendas; entre elas, há uma padronização de parâmetros técnicos - como número máximo de caracteres por linha $(\mathrm{CPL})$ e de caracteres exibidos por segundo (CPS) - que são requisitos de publicação. As séries são distribuídas a equipes exclusivas e, até um prazo estipulado pelo site, apenas o grupo atribuído ao programa pode postar uma tradução. Essas traduções exclusivas ganham destaque na página inicial do site e, para que continuem assim, devem seguir os seguintes parâmetros técnicos:

a. limite de 32 caracteres por linha (CPL);

b. $\quad$ máximo de 2 linhas por legenda;

c. tempo de exposição mínimo de 1.3 segundos;

d. $\quad$ tempo de exposição máximo de 5 segundos;

e. $\quad$ máximo de 20 caracteres por segundo (CPS);

f. com espaço após o travessão (hífen);

g. não possuir asteriscos ou frases/palavras não traduzidas;

h. não usar nenhum tipo de tradutor automático.

i. Além dos padrões técnicos, todas as legendas terão a tradução e a ortografia/gramática analisadas. (Legendas.tv ${ }^{11}$ )

Esses parâmetros são importantes para que as legendas possam ser lidas em tempo hábil e sejam compatíveis com os diversos dispositivos de reprodução disponíveis, como computadores, smarphones e smart TVs. Para garantir que essas normas de qualidade sejam seguidas, a InSUBs divide tarefas: assim que passa no teste de recrutamento da equipe, um legender iniciante é chamado de rookie, ou novato. Ele passará por um treinamento e por avaliações antes de se tornar efetivo. Legenders efetivos podem traduzir qualquer série ou filme atribuído à equipe de forma dividida: cada legender fica responsável por traduzir um determinado intervalo de tempo do programa, que varia entre 5 e 10 minutos.

\footnotetext{
${ }^{11}$ Disponível em: <http://legendastv.freshdesk.com/support/solutions/articles/1000129865-regrasgerais-para-destaques->. Acesso em 29 jun. 2018
} 
Para designar o trecho escolhido, o voluntário deve reservar uma vaga de tradução nas chamadas em aberto no sistema da equipe, conhecido como "InSUBs Manager", ilustrado na Figura 1:

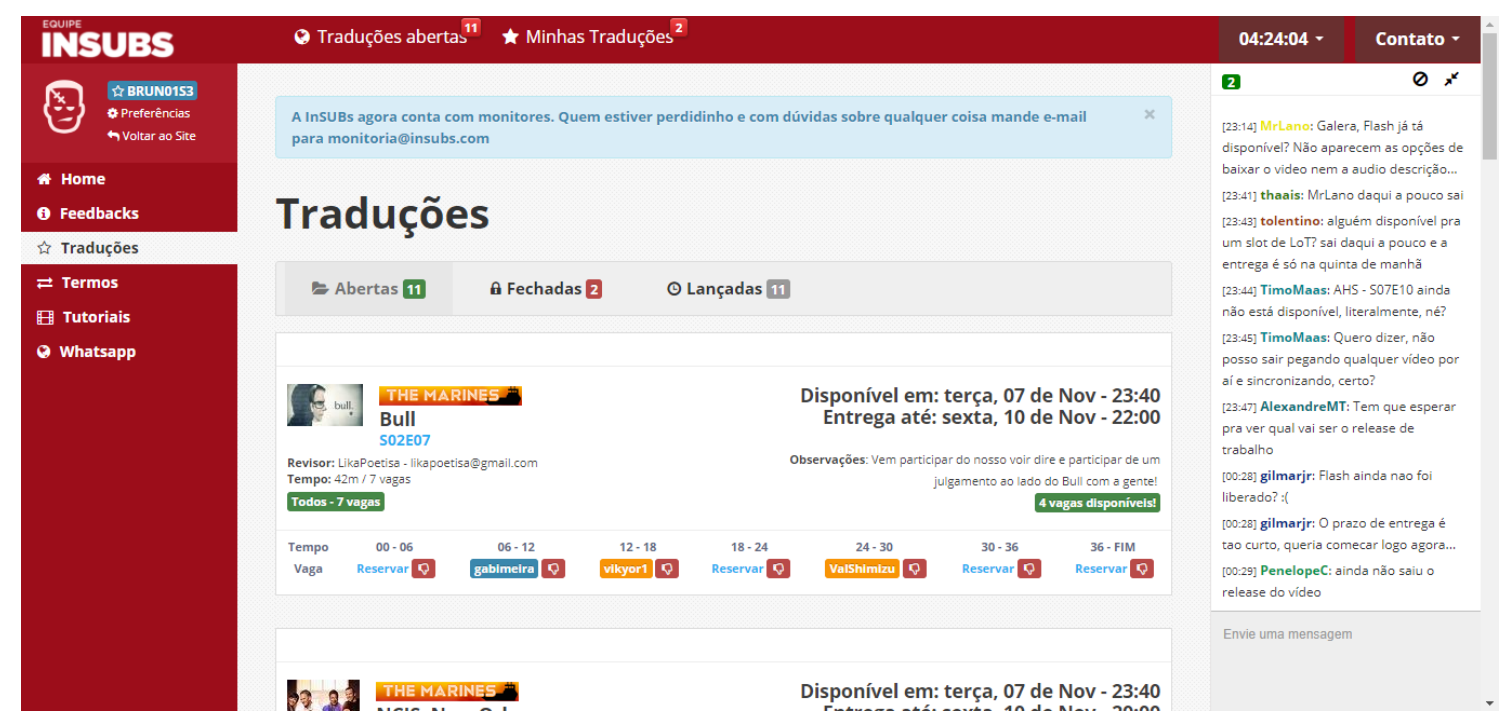

Figura 1: 0 sistema interno da InSUBs, chamado de Manager. No menu à esquerda, vemos as principais ferramentas disponíveis no sistema; no centro, temos as chamadas de tradução em aberto; à direita, há um bate-papo interno.

o Manager é uma invenção recente: anteriormente, a equipe se comunicava apenas por e-mail e por mensageiros eletrônicos. Tanto as chamadas quanto os pedidos de reserva de vaga eram combinadas por correio eletrônico, o que gerava duplicidade de reservas e outros conflitos. Assim, o sistema foi criado para centralizar ferramentas, legenders e chamadas em um ambiente digital muito mais prático e seguro.

Entre as ferramentas disponíveis no Manager, encontramos um rico glossário de termos específicos de cada série. Atualmente, o acervo de termos e expressões conta com 946 entradas e inclui siglas padronizadas, formas de tratamento, nomes e apelidos de personagens traduzidos e terminologias específicas. Esse glossário representa um elemento de padronização dentro da equipe: ele evita que personagens sejam chamados de nomes diferentes entre os episódios ou que termos recorrentes sejam traduzidos de forma equivocada.

Além do glossário, o Manager também fornece uma página de feedback. Assim que os legenders enviam seus intervalos traduzidos no site, um revisor 
(fixo à série) avaliará a tradução a fim de verificar se os parâmetros técnicos e estilísticos estabelecidos pelo Legendas.TV e pela equipe foram contemplados nas traduções. É também papel do revisor checar se termos recorrentes estão sendo traduzidos com consistência e seguindo as diretrizes do glossário, além de corrigir a sincronia da legenda, que também deve ser observada pelo legender que a traduziu. De acordo com essa avaliação, é emitido um feedback ao tradutor voluntário com notas entre 0 e 5 para tradução e sincronia.

Todos esses elementos garantem que a legenda tenha um padrão de qualidade e estilo, sendo também importante para a "formação" dos legenders, já que o glossário, os guias de estilo e gramática e a avaliação dos revisores são considerados ensinamentos dos mais experientes aos que estão começando.

Todo esse processo é realizado de forma voluntária: os fãs se dispõem a produzir legendas de suas séries favoritas pelo prazer de participar da comunidade e de interagir com o produto em si. Embora não haja um ganho financeiro, no entanto, é possível afirmar que o prestígio dentro dessa comunidade seja um fator decisivo no trabalho voluntário. PenelopeC, por exemplo, é uma tradutora profissional de legendas que dedica suas horas vagas à tradução voluntária. Ela afirma que, enquanto o trabalho profissional é "invisível" e solitário, a prática legender traz consigo toda a admiração e a gratidão das comunidades de fãs. No Legendas.TV, em que os usuários podem deixar seus comentários sobre a legenda produzida, é muito comum encontrar elogios e mensagens de agradecimento como as seguintes apresentadas na Figura 2: 


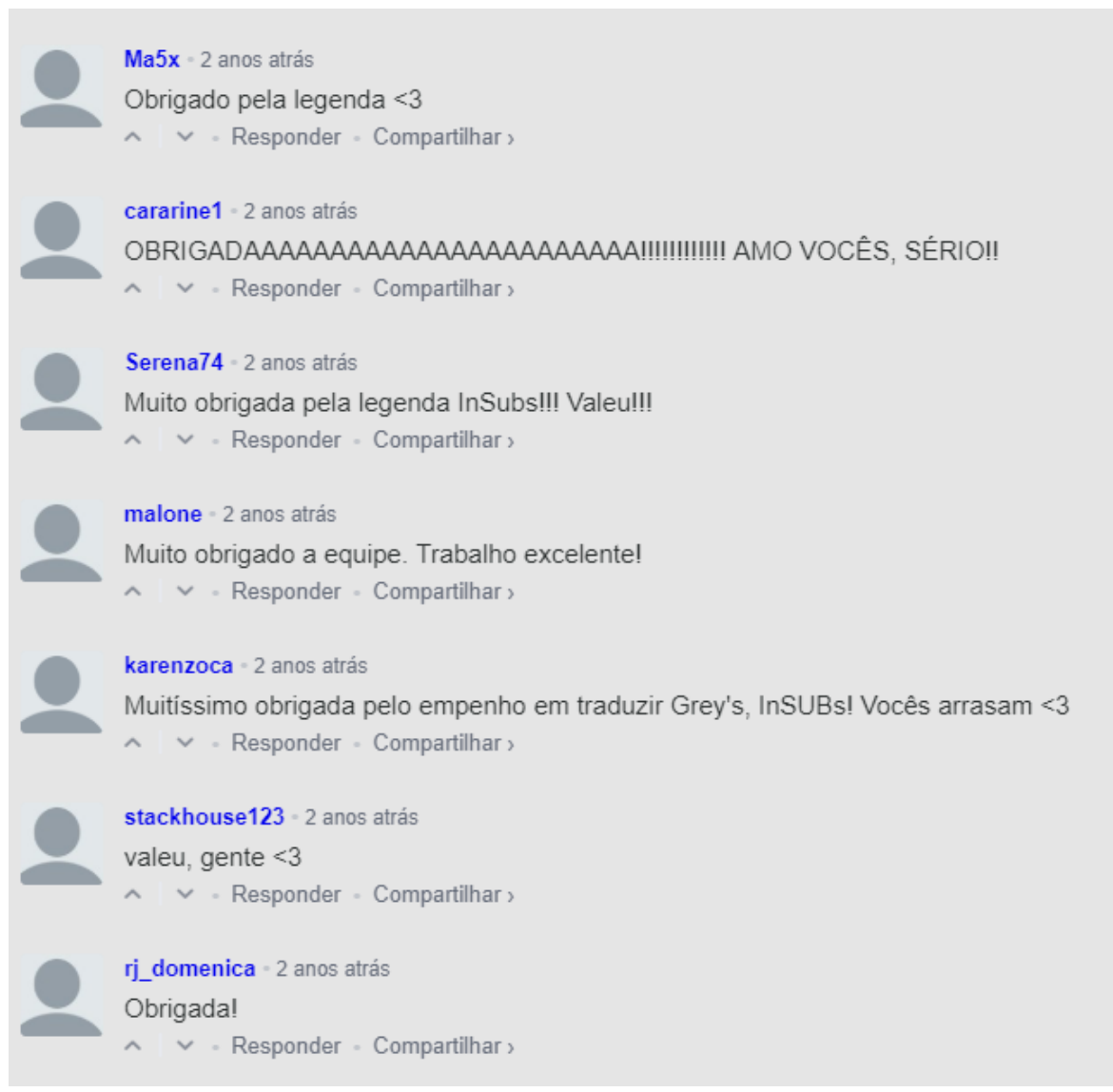

Figura 2: Caixa de comentários do episódio de estreia da $13^{\mathrm{a}}$ temporada de Grey's Anatomy no site Legendas.TV.

De fato, o reconhecimento dos fãs é o pagamento da equipe: é essa valorização do trabalho que recompensa os legenders e que os coloca em posição competitiva em relação às outras equipes: os grupos se dedicam, entre outras coisas, em função da visibilidade. Como explica Spolidorio (2017),

ainda que a maioria dos grupos afirme categoricamente que não fazem as legendas pelo status nem pelo reconhecimento, seria ingenuidade acreditar que esses elementos não são um fator de influência, uma vez que, dentro das comunidades online, a persona construída na interação virtual (chamada de avatar) tem um alto valor social para quem participa, muitas vezes suplantando até valores e interações de outras esferas sociais de interação como lugar de estudo ou trabalho. Como foi apresentado por Lefevere (1992), todas as forças físicas, políticas, históricas ou sociais que, de alguma forma, motivam ou restringem a tradução de um texto podem ser consideradas formas de patronagem. Assim, é possível interpretar esse aberto reconhecimento e explicita gratidão de fãs nas comunidades virtuais como uma dessas formas de patronagem. (SPOLIDORIO 2017: 96). 
O sentido competitivo é outro fator que justifica o desenvolvimento da InSUBs, bem como o de outras equipes de legendagem voluntária: além do aspecto afetivo e social, a prática também traz admiração e reconhecimento e, quanto melhor uma equipe se desempenha em suas traduções, mais bem vistos são seus integrantes dentro da comunidade.

Assim, a legendagem voluntária no Brasil prospera; com o crescente acesso às séries estrangeiras, tanto por canais extraoficiais quanto pela popularização de serviços como a Netflix, o trabalho dos legenders atende a uma demanda frenética de fãs e consumidores casuais de filmes e seriados. $\mathrm{Na}$ seção a seguir, veremos quais mudanças ocorreram na prática legender, e em especial na InSUBs, em relação à qualidade da tradução e da pesquisa terminológica. Considerando que Grey's Anatomy é uma das principais séries traduzidas pela equipe e que possui um volume considerável de terminologia médica em seus diálogos, selecionamos algumas legendas do seriado para analisar o desenvolvimento do trabalho de legendagem voluntária de forma cronológica e, em seguida, compará-las ao trabalho contratado por serviços como a Netflix e, assim, reconhecido como profissional.

\section{Do zero ao zelo: o desenvolvimento da}

\section{InSUBs.}

A fim de investigar a evolução da prática legender com o decorrer do tempo, selecionamos treze episódios de Grey's Anatomy - o primeiro de cada temporada - e procuramos, nas legendas, termos médicos ou diálogos inseridos em primeiros-socorros, cirurgias e outros procedimentos hospitalares. Comparamos, então, a tradução dos legenders para esses termos às legendas disponibilizadas na Netflix, fundamentando-nos em dicionários médicos como o Stedman's Medical Dictionary (2003) e o Dorland's Illustrated Medical Dictionary (1994). Também utilizamos materiais especializados, encontrados em bancos de artigos ou em páginas eletrônicas dedicadas à medicina, como a da Biblioteca Nacional de Medicina dos Estados Unidos. 
De acordo com nossa análise, sem o estabelecimento de parâmetros técnicos e estilísticos, o primeiro episódio de Grey's Anatomy legendado por um tradutor voluntário do Só Séries apresentava traduções discutíveis de termos básicos, como scalp, cuja tradução no Stedman's Medical Dictionary (2013: 1420) é "bisturi”, e foi traduzido como "escalpe" (que não encontra definição em dicionários como o Aurélio Dicionário Online de Português) e o Aulete on-line, mas que se aproxima mais de "escalpo", definido como "a pele e o tecido subcutâneo, normalmente com cabelos, que recobrem o neurocrânio" pelo Stedman's Medical Dictionary (STEDMAN 2003: 1420). Também encontramos, no mesmo episódio, o termo "female", para se referir a uma paciente humana, traduzido como "fêmea", termo mais utilizado para animais e plantas, conforme o Aulete on-line.

O primeiro episódio revela que a legendagem voluntária individual, sem a definição de regras e tarefas, era muito provavelmente realizada com tradutores automáticos ou com leituras descuidadas do contexto geral em que o diálogo está inserido. Essas estratégias eram adotadas devido ao curto período de tempo em que apenas uma pessoa deveria traduzir as legendas para disponibilizá-las antes dos outros legenders. Opções incertas de tradução são encontradas até a quarta temporada da série, como no exemplo a seguir, em que contrastamos as opções produzidas pelo tradutor da Netflix e pelos tradutores voluntários. Na cena, um dos médicos, Alex Karev [AK] solicita instrumentos à enfermeira para socorrer o bebê:

\begin{tabular}{|l|l|}
\hline \multicolumn{2}{|c|}{$\begin{array}{l}\text { LEGENDA ORIGINAL } \\
\text { [AK]-Get me an l.O. needle, }\end{array}$} \\
\hline \multicolumn{1}{|c|}{ And I need a neonatal intubation kit. } \\
\hline NETFLIX & \multicolumn{1}{c|}{ FANSUB } \\
$\begin{array}{l}\text { [AK]- Me dê uma agulha IO, e } \\
\text { preciso de um kit de entubação } \\
\text { neonatal. }\end{array}$ & $\begin{array}{l}\text { [AK]- Me arranje uma seringa, e eu } \\
\text { preciso de um kit de entubação para } \\
\text { recém-nascidos. }\end{array}$ \\
\hline
\end{tabular}

Nessa legenda, identificamos que a tradução de "I.O. needle", instrumento conhecido em português como "agulha de infusão intra-óssea", 
de acordo com registros da ANVISA", é reduzido a "seringa" na legenda voluntária. É um exemplo de como a interpretação era realizada de forma superficial e, muitas vezes, inexata, antes da organização dos trabalhos pela InSUBs: uma seringa pouquíssimo se assemelha, em formato ou função, a uma agulha capaz de penetrar ossos.

A InSUBs demorou algum tempo para se organizar e sedimentar suas técnicas de tradução e pesquisa terminológica: ainda nas primeiras temporadas traduzidas pela equipe, encontramos escolhas muito abrangentes ou inadequadas para traduzir alguns termos, como pode ser visto na legenda a seguir, da quinta temporada, em que, durante uma cirurgia para recuperar os danos no braço da paciente, Meredith Grey [MG] e George O'Malley [GO] são acompanhados por Mark Sloan [MS]. Os médicos percebem que a paciente está prestes a dar à luz:

\begin{tabular}{|l|l|}
\hline \multicolumn{2}{|c|}{$\begin{array}{l}\text { LEGENDA ORIGINAL } \\
\text { [GO]- Her water broke. }\end{array}$} \\
[MS]- Call Peds. Get a warmer in here. Baby's coming. \\
\hline \multicolumn{1}{|c|}{ NETFLIX } & \multicolumn{1}{c|}{ FANSUB } \\
$\begin{array}{l}\text { [GO]- A bolsa se partiu. } \\
\text { [MS]- Peça uma incubadora à } \\
\text { Pediatria. O bebê vai nascer. }\end{array}$ & [Golá - bolsa rompeu, e o bebê \\
& Tragam cobertores. \\
\hline
\end{tabular}

O termo "warmer", que se refere à incubadora, conforme definição da Biblioteca Nacional de Medicina dos Estados Unidos' ${ }^{13}$, é traduzido como "cobertores" pela InSUBs. A escolha por "cobertor" oferece uma leitura incompatível com a imagem mostrada na cena, em que os médicos buscam uma incubadora, aparelho para o tratamento emergencial de recém-nascidos prematuros.

É possível observar uma evolução na pesquisa terminológica das legendas produzidas pela equipe de voluntários. A tabela a seguir apresenta

\footnotetext{
${ }^{12}$ Disponível em: <https://www.smerp.com.br/anvisa/?ac=prodDetail\&anvisald=10212990115>. Acesso em 16 jul. 2018.

${ }^{13}$ Disponível em: <https://www.ncbi.nlm.nih.gov/pubmed/6641579>. Acesso em 1 jul. 2018.
} 
resumidamente os termos analisados com base nos dicionários consultados neste item. Ela foi produzida a partir das análises de cada episódio de estreia de temporada, nos quais foram selecionados termos técnicos da área médica, para cotejamento das traduções realizadas pelos legenders e pelos legendadores do Netflix. Tanto as legendas voluntárias quanto as contratadas tiveram sua terminologia examinada com base nos dicionários médicos que embasaram esta pesquisa com o objetivo de identificar quais traduções se aproximavam mais da terminologia normatizada na medicina. Na segunda coluna da tabela, explicamos como se encontrava a prática fansub/legender durante as temporadas analisadas - os perfis foram traçados com base na terminologia analisada (o que nos mostrou o nível maturidade da pesquisa terminológica no intervalo em questão) e nas entrevistas realizadas com os membros da InSUBs. Também consideramos nessa análise o emprego de parâmetros técnicos e estilísticos para construirmos uma interpretação mais esclarecedora sobre o desenvolvimento da equipe. Já a terceira coluna da tabela apresenta os principais termos analisados, indicando as escolhas tradutórias da equipe em itálico e a melhor sugestão, fornecida por dicionários e materiais especializados, em formatação normal. Nos casos em que a equipe empregou a opção considerada mais adequada, assinalamos com "OK":

\begin{tabular}{|c|c|c|}
\hline TEMPORADA & SITUAÇÃO & $\begin{array}{l}\text { EXEMPLOS DE } \\
\text { TRADUÇÃO DA INSUBS } \\
\text { (Empregado - melhor } \\
\text { sugestão) }\end{array}$ \\
\hline $\begin{array}{l}1 \text { a } 3 \\
\text { Correspondência } \\
\text { mínima, } \\
\text { pesquisa } \\
\text { terminológica } \\
\text { inexistente. }\end{array}$ & $\begin{array}{l}\text { Legendas realizadas por } \\
\text { voluntários individuais. Os } \\
\text { termos médicos eram traduzidos } \\
\text { de forma inexata e as siglas } \\
\text { mantidas em suas formas } \\
\text { originais. A diferença para a } \\
\text { legenda profissional é bem } \\
\text { marcada. }\end{array}$ & $\begin{array}{l}\text { Escalpe - bisturi } \\
\text { Fêmea - feminino } \\
C B C \text {, chem-7, tox } \\
\text { screen - mantidos em } \\
\text { inglês. } \\
\text { Seringa - agulha I.O. }\end{array}$ \\
\hline $\begin{array}{l}4 \text { a } 6 \\
\text { Correspondência } \\
\text { iniciante, } \\
\text { pesquisa } \\
\text { terminológica } \\
\text { em seus }\end{array}$ & $\begin{array}{l}\text { Legendas passam a ser } \\
\text { realizadas pela InSUBs. Embora } \\
\text { a pesquisa terminológica pareça } \\
\text { começar a dar seus primeiros } \\
\text { passos, ainda é imprecisa e } \\
\text { equívocos são cometidos com }\end{array}$ & $\begin{array}{l}\text { Cobertores - } \\
\text { incubadora. } \\
\text { Trendelenburg } \\
\text { reverso -OK. } \\
\text { Penfield curvado- } \\
\text { OK. }\end{array}$ \\
\hline
\end{tabular}




\begin{tabular}{|c|c|c|}
\hline $\begin{array}{l}\text { primeiros } \\
\text { passos. }\end{array}$ & $\begin{array}{l}\text { frequência. A precisão técnica } \\
\text { começa a aparecer na quinta } \\
\text { temporada. }\end{array}$ & $\begin{array}{l}\text { Fratura por } \\
\text { compressão - OK. }\end{array}$ \\
\hline $\begin{array}{l}7 \text { a } 9 \\
\text { Correspondência } \\
\text { mediana, } \\
\text { pesquisa } \\
\text { terminológica } \\
\text { mais expressiva. }\end{array}$ & $\begin{array}{l}\text { As legendas da InSUBs tornam-se } \\
\text { mais precisas, e o caráter oral } \\
\text { começa a ser observado no } \\
\text { estilo da equipe. Embora ainda } \\
\text { haja algumas incorreções, } \\
\text { outros termos são traduzidos de } \\
\text { forma mais genérica, o que } \\
\text { indica, pelo menos, a realização } \\
\text { de pesquisa terminológica. } \\
\text { Nomes de substâncias e } \\
\text { medicamentos são traduzidas de } \\
\text { forma precisa. }\end{array}$ & $\begin{array}{l}\text { Tumor - cordoma; } \\
\text { tipo de tumor (OK). } \\
\text { Pneumotórax - OK. } \\
\text { Tronco cerebral - OK. } \\
\text { Síndrome da fome } \\
\text { óssea - OK. }\end{array}$ \\
\hline $\begin{array}{l}10 \text { a } 13 \\
\text { Correspondência } \\
\text { avançada/total; } \\
\text { pesquisa } \\
\text { terminológica } \\
\text { mais } \\
\text { consistente. }\end{array}$ & $\begin{array}{l}\text { Embora a legenda produza } \\
\text { equívocos no sentido na décima } \\
\text { temporada, ela passa a se } \\
\text { equiparar de forma notável à } \\
\text { legenda profissional e, em } \\
\text { alguns casos, se mostra mais } \\
\text { precisa, a partir da temporada } \\
11 .\end{array}$ & $\begin{array}{l}\text { ECG (Escala de Coma } \\
\text { de Glasgow) - OK; } \\
\text { mantida em inglês } \\
\text { (GCS) pela legenda } \\
\text { profissional. } \\
\text { Subaracnóideo - OK. } \\
\text { Pienolefrite - OK. } \\
\text { Ducto colédoco - OK. }\end{array}$ \\
\hline
\end{tabular}

Pela tabela podemos constatar que, nas primeiras seis temporadas, os legenders ainda não haviam formalizado suas estratégias de tradução e adequação técnica das legendas. As traduções indicam certa inexperiência dos voluntários, uma vez que elencam termos inadequados ou distantes da terminologia padrão, produzindo discursos confusos ou pouco esclarecedores acerca dos procedimentos narrados pelos personagens.

A partir da sétima temporada, no entanto, nota-se uma mudança considerável nas técnicas adotadas pelos legenders: além do estabelecimento de parâmetros técnicos, as traduções também se tornaram mais criteriosas e demonstram maior preocupação com a pesquisa terminológica. Os termos escolhidos pela InSUBs aproximam-se mais dos profissionais e, em alguns casos, apresentam alto grau de precisão terminológica. As traduções, nessa fase de trabalho da equipe voluntária, são realizadas com mais segurança, mesmo quando os termos precisam ser reduzidos para que caibam no limite de $\mathrm{CPL}$ ou para que sejam mais facilmente interpretados pelo telespectador. 
Como exemplo, temos o termo "cordoma", mostrado na terceira linha da tabela: ele foi traduzido como "tumor" pelos legenders, o que reduz tanto o número de caracteres por linha quanto simplifica o termo para que seja compreendido por um público leigo: de acordo com o Dorland's Medical Dictionary, cordoma é um "tumor maligno que surge a partir dos restos embrionários do notocórdio" (DORLAND 1994: 162). Na tabela abaixo, é possível observar o efeito que essa escolha produz na legenda em termos de simplificação e redução de volume textual. A fala ocorre quando a médica April Kepner [AK] relata o que encontrou no exame de um paciente de Derek Shepherd, chefe da neurocirurgia.

\begin{tabular}{|c|c|}
\hline $\begin{array}{l}\text { LEGEND } \\
\text { [AK]-Chief, you're back. I fo } \\
\text { Biggest one I've ever seen. He cam }\end{array}$ & $\begin{array}{l}\text { ORIGINAL } \\
d \text { a giant skull base chordoma. } \\
\text { in to the ER with trouble breathing. }\end{array}$ \\
\hline $\begin{array}{l}\text { NETFLIX } \\
\text { [AK]- Você voltou! Encontrei um } \\
\text { gigantesco cordoma na base do } \\
\text { crânio. O maior que já vi. O garoto } \\
\text { chegou com dificuldade de respirar. }\end{array}$ & $\begin{array}{l}\text { FANSUB } \\
\text { [AK]-Chefe, você voltou. Achei um } \\
\text { tumor enorme. O maior que já vi. } \\
\text { Chegou no PS com problemas } \\
\text { respiratórios. }\end{array}$ \\
\hline
\end{tabular}

A redução de "gigantesco cordoma na base do crânio" é resolvida com "tumor enorme": embora pareça simplificar demais e omitir detalhes, como "na base do crânio", a legenda tem, como complemento, o contexto, uma vez que o caso já havia sido mostrado anteriormente no mesmo episódio e que, em cenas seguintes, há imagens de tomografia computadorizada evidenciando a localização do tumor.

No intervalo seguinte, que começa com a décima temporada, há também a tradução de uma sigla: GCS, que em inglês significa Glasgow Coma Scale, é apropriadamente traduzida pela equipe como ECG, respaldada pela definição do Stedman's Medical Dictionary como "Escala de Coma Glasgow" (STEDMAN 2003: 665). Essa ocorrência parece sinalizar certa "maturidade" da equipe em relação à pesquisa terminológica: houve o cuidado de encontrar o significado da sigla original e um correspondente para ela em língua portuguesa. Esse é um caso em que a legenda voluntária parece ser mais precisa do que a profissional, que manteve a sigla em inglês na legenda. 
$\mathrm{Na}$ décima terceira temporada, constatamos que os termos foram traduzidos pela InSUBs de acordo com as sugestões encontradas em dicionários e materiais especializados, sugerindo uma considerável evolução nas técnicas empregadas nas legendas. Nossa análise indicou que a adequação das traduções, em termos de padronização técnica e investigação terminológica, mostrou-se notavelmente crescente ao longo dos anos em que a equipe traduziu a série. Esse aprimoramento pode ser explicado em função do desenvolvimento dos parâmetros de controle das traduções adotados pela equipe, como a verificação de limites técnicos, padronização de termos, revisões dedicadas e atenção ao feedback dos usuários.

Para entendermos o efeito prático dessas medidas empregadas pela equipe, realizamos um teste com seis participantes, sendo três usuários, dois legenders e um tradutor profissional da Netflix. Os respondentes foram convidados a assistir a dez cenas de episódios de Grey's Anatomy, todos eles episódios de estreia de temporada, exibidos de forma aleatória. A cena era repetida duas vezes, sendo que uma delas era legendada pela InSUBs e a outra pela Netflix. Seguindo uma escala de certeza, o participante deveria assinalar qual legenda acreditava ser a voluntária e justificar sua resposta. A Figura 4 apresenta como o teste foi apresentado aos respondentes:

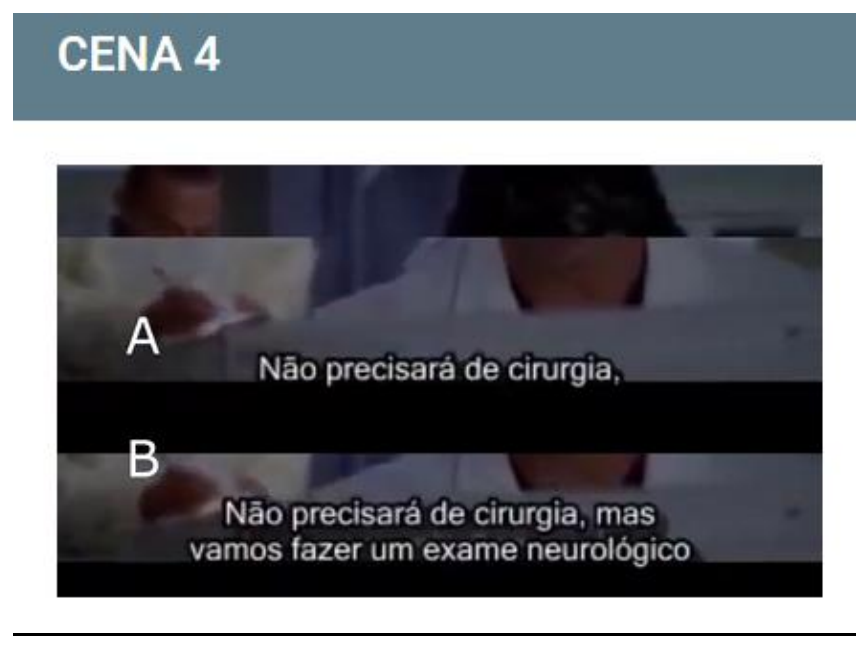

Figura 4: Vídeos exibidos aos participantes com legendas identificadas como A e B, sendo uma delas a profissional e a outra produzida pela InSUBs. 
Qual legenda é AMADORA? *

Utilize a escala de certeza da seguinte forma: Se você tem certeza que é A, coloque 1. Quase certeza que é A, 2. Neutro, 3. Quase certeza que é B, 4. Certeza que é B, 5.

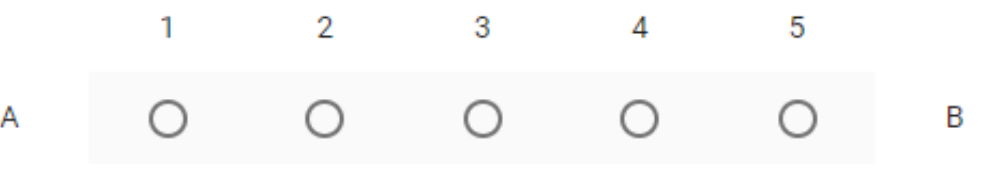

Justificativa *

Explique de forma simples, mas detalhada, suas impressões sobre as legendas, justificando sua resposta à pergunta acima.

Sua resposta

Qual legenda você considera melhor?

Com base em qual legenda te agradaria mais ao assistir a cena, em termos de eficiência de tradução, tempo de exibição da legenda, palavras utilizadas, ou qualquer outro critério que você deseje.

A

в

Ambas possuem a mesma qualidade

Por quê? *

Justifique sua resposta à pergunta acima.

Sua resposta

Figura 5: Tela do teste realizado com seis participantes.

O objetivo do teste foi entender se a legenda voluntária poderia se passar por profissional e, se afirmativo, com que frequência e a partir de quando. Os resultados obtidos foram interessantes: a partir da quarta temporada, quando a InSUBs assumiu as legendas, a legenda voluntária começa a ser apontada pelos participantes como profissional, sendo que apenas dois dos últimos seis episódios exibidos tiveram as legendas assinaladas corretamente. Além da identificação da legenda voluntária como superior, a preferência por ela foi marcada pela maior parte dos participantes em todos os episódios a partir da quinta temporada, sendo que apenas a décima apresentou um empate, como resume a tabela a seguir: 


\begin{tabular}{|c|c|c|c|c|c|}
\hline TEMP. & $\begin{array}{l}\text { LEGENDA } \\
\text { AMADORA }\end{array}$ & $\begin{array}{l}\text { LEGENDA + } \\
\text { APONTADA } \\
\text { COMO } \\
\text { AMADORA }\end{array}$ & $\begin{array}{l}\text { PARÂMETROS } \\
\text { DE } \\
\text { JULGAMENTO }\end{array}$ & $\begin{array}{l}\text { PREFERẾNCIA } \\
\text { (e número de } \\
\text { votos) }\end{array}$ & $\begin{array}{l}\text { JUSTIFICATIVA } \\
\text { DE PREFERÊNCIA }\end{array}$ \\
\hline 1 & B & B & $\begin{array}{l}\text { Quebra de } \\
\text { linha, } \\
\text { sentido } \\
\text { coloquial, } \\
\text { atrasos. }\end{array}$ & $\begin{array}{l}\text { PROF. } \\
\text { A - } 3 \\
\text { Ambas - } 2 \\
\text { B - } 1\end{array}$ & $\begin{array}{l}\text { Frases mais } \\
\text { curtas, } \\
\text { tradução, } \\
\text { conforto de } \\
\text { leitura. }\end{array}$ \\
\hline 2 & $A$ & $\begin{array}{l}\text { Dúvida (com } \\
\text { tendência à } \\
\text { A) }\end{array}$ & $\begin{array}{l}\text { Erros de } \\
\text { tradução, } \\
\text { erros de } \\
\text { pontuação, } \\
\text { sincronia. }\end{array}$ & $\begin{array}{l}\text { PROF. } \\
\text { B - } 4 \\
\text { A - } 1 \\
\text { Ambas- } 1\end{array}$ & $\begin{array}{l}\text { Legenda mais } \\
\text { precisa, tempo } \\
\text { de tela e } \\
\text { condensação do } \\
\text { texto. }\end{array}$ \\
\hline 4 & B & A & $\begin{array}{l}\text { Erros de } \\
\text { tradução, } \\
\text { erros de } \\
\text { pontuação, } \\
\text { sincronia. }\end{array}$ & $\begin{array}{l}\text { PROF. } \\
\text { Ambas - } 3 \\
\text { A - } 2 \\
\text { B - } 1\end{array}$ & $\begin{array}{l}\text { Grafia } \\
\text { (acentuação), } \\
\text { sincronia e } \\
\text { forma de tratar } \\
\text { o sentido } \\
\text { figurado. }\end{array}$ \\
\hline 5 & $\mathrm{~A}$ & Dúvida & $\begin{array}{l}\text { Escolha de } \\
\text { palavras, } \\
\text { traduções } \\
\text { incorretas e } \\
\text { sincronia. }\end{array}$ & $\begin{array}{l}\text { PROF. } \\
\text { Ambas - } 3 \\
\text { B - } 2 \\
\text { A - } 1\end{array}$ & $\begin{array}{l}\text { Condensação do } \\
\text { texto, quebra } \\
\text { de linha, termos } \\
\text { técnicos } \\
\text { traduzidos } \\
\text { corretamente. }\end{array}$ \\
\hline 7 & $B$ & $A$ & $\begin{array}{l}\text { "A legenda B } \\
\text { possui menos } \\
\text { erros que a } \\
\text { A" }\end{array}$ & $\begin{array}{l}\text { AMAD. } \\
\text { B- } 5 \\
\text { A - } 1\end{array}$ & $\begin{array}{l}\text { Condensação do } \\
\text { texto, } \\
\text { "tradução mais } \\
\text { enxuta”, } \\
\text { tradução mais } \\
\text { clara e } \\
\text { adequada. }\end{array}$ \\
\hline 8 & $A$ & $A$ & $\begin{array}{l}\text { Quebra de } \\
\text { linha, } \\
\text { traduções } \\
\text { inadequadas } \\
\text { e literais }\end{array}$ & $\begin{array}{l}\text { AMAD. } \\
\text { A - } 3 \\
\text { Ambas - } 2 \\
B-1\end{array}$ & $\begin{array}{l}\text { Tempo de tela } \\
\text { mais adequado } \\
\text { e leitura mais } \\
\text { fluída. }\end{array}$ \\
\hline 9 & $A$ & B & $\begin{array}{l}\text { Pontuações } \\
\text { desnecessári } \\
\text { as, tempo de } \\
\text { exposição, } \\
\text { abreviação e } \\
\text { literalidade. }\end{array}$ & $\begin{array}{l}\text { AMAD. } \\
\text { A - } 3 \\
\text { Ambas - } 2 \\
B-1\end{array}$ & $\begin{array}{l}\text { Pontuação e } \\
\text { erro de } \\
\text { abreviação } \\
\text { (“hrs”) na } \\
\text { legenda } \\
\text { profissional. }\end{array}$ \\
\hline 10 & $A$ & $B$ & $\begin{array}{l}\text { Legendas } \\
\text { bem } \\
\text { semelhantes, } \\
\text { de coerência } \\
\text { e pontuação }\end{array}$ & $\begin{array}{l}\text { EMPATE } \\
2 / 2 / 2\end{array}$ & $\begin{array}{l}\text { Legendas } \\
\text { semelhantes, } \\
\text { facilidade de } \\
\text { leitura, quebra } \\
\text { de linha. }\end{array}$ \\
\hline 11 & B & A & $\begin{array}{l}\text { Legendas } \\
\text { bem } \\
\text { semelhantes, }\end{array}$ & $\begin{array}{l}\text { AMAD. } \\
\text { B - } 4 \\
\text { Ambas - } 1\end{array}$ & $\begin{array}{l}\text { Sincronia, } \\
\text { escrita mais } \\
\text { fluente, }\end{array}$ \\
\hline
\end{tabular}

TradTerm, São Paulo, v. 33, maio/2019, p. 26-53 www. revistas.usp.br/tradterm 


\begin{tabular}{|l|l|l|l|l|l|}
\hline & & & $\begin{array}{l}\text { erro de } \\
\text { sincronia, } \\
\text { formatação } \\
\text { em itálico na } \\
\text { legenda } \\
\text { amadora. }\end{array}$ & A - 1 & $\begin{array}{l}\text { pontuação mais } \\
\text { clara. }\end{array}$ \\
\hline 12 & B & B & $\begin{array}{l}\text { "A legenda B } \\
\text { é mais } \\
\text { literal” }\end{array}$ & $\begin{array}{l}\text { AMAD. } \\
\text { B - 4 } \\
\text { A - 2 }\end{array}$ & $\begin{array}{l}\text { Timing, fluência } \\
\text { do texto, } \\
\text { condensação de } \\
\text { texto, quebra } \\
\text { de linha. }\end{array}$ \\
\hline
\end{tabular}

Com base nos resultados desse teste, é possível constatar que, a partir da temporada quatro, a primeira traduzida pela InSUBs, a legenda voluntária começa a ser confundida com a profissional: cinco das oito legendas foram confundidas. Até mesmo o tradutor profissional da Netflix ficou em dúvida sobre algumas legendas, assinalando várias traduções voluntárias como profissionais. Além disso, é importante destacar que, a partir da sétima temporada (justamente a que constatamos, na análise anterior, ser o ponto de partida das mudanças significativas nas técnicas empregadas pela equipe), os participantes do teste assinalam preferência pela legenda voluntária, mesmo sem saber que se tratava dela.

Os pontos mencionados por eles para justificar sua preferência são os mesmos que indicamos como decisivos no desenvolvimento da equipe: a InSUBs adotou métodos de pesquisa e de tradução terminológica, como o uso de glossários, fazendo com que as traduções se tornassem mais compatíveis, padronizadas e coerentes com os contextos médicos apresentados em Grey's Anatomy. Também foram apontados critérios que remetem à padronização técnica, como legendas mais curtas e sintetizadas, termos mais acessíveis a públicos leigos, espaço ocupado pela legenda em tela e tempo hábil para leitura.

De fato, se compararmos a legenda profissional à voluntária em termos técnicos, não fica clara uma padronização de parâmetros técnicos na legenda da Netflix, enquanto a legenda voluntária os segue à risca. Foi possível comprovar esse fato com o uso do Subtitle Workshop 6.0: o programa é amplamente utilizado pelos legenders por ser gratuito e conter ferramentas 
muito úteis, principalmente para o cumprimento de limites técnicos. 0 Subtitle Workshop fornece um relatório detalhado sobre a média de caracteres por linha e por segundo, entre outros fatores. Comparando as legendas (do episódio 1, temporada 13) temos a seguinte tabela:

\begin{tabular}{|l|l|l|}
\hline & NETFLIX & INSUBS \\
\hline MAIOR CPS & 50 & 33 \\
\hline CPS MÉDIO & 16 & 14 \\
\hline MAIOR CPL & 42 & 32 \\
\hline $\begin{array}{l}\text { MENOR DURAÇÃO NA } \\
\text { TELA }\end{array}$ & $0,8 \mathrm{~s}$ & $1,3 \mathrm{~s}$ \\
\hline
\end{tabular}

Os índices listados significam, em resumo, que a legenda voluntária fica mais tempo na tela, possui menos caracteres por linha e apresenta um número menor de caracteres que precisam ser lidos por segundo, antes do desaparecimento da legenda.

Nossa análise indica que a legenda voluntária evoluiu em aspectos técnicos e terminológicos no decorrer do tempo, embora tenha começado como uma prática aparentemente desorganizada e mal articulada. As evoluções devem-se principalmente às necessidades de inovação da equipe em termos de tecnologia e estratégias de tradução, em função dos parâmetros técnicos exigidos pelo Legendas.TV e do feedback fornecido pelos usuários. Esse amadurecimento resultou em traduções mais padronizadas e mais congruentes com as expectativas dos usuários.

A qualidade das legendas voluntárias é tão notável atualmente que até mesmo canais da televisão por assinatura utilizam o trabalho dos legenders nos episódios que transmitem, mesmo sem comunicar as equipes. Algumas dessas legendas "emprestadas" pelas emissoras são facilmente identificáveis como voluntárias, uma vez que carregam marcas registradas da equipe que a produziu - a equipe InSanos, por exemplo, utiliza sempre o próprio nome, com o S maiúsculo, para traduzir palavras como crazy, insane, mad, etc. À parte as questões éticas desse "empréstimo" por parte das emissoras, 
podemos dizer que isso valida a legenda voluntária como produto bemsucedido de esforços comunitários.

Se, no início, a prática caminhava a passos incertos e inseguros, hoje ela demonstra uma maturidade conquistada por meio de empenho, pesquisa e amor pelas séries e pela comunidade de fãs. É impossível olhar para o trabalho dos legenders e considerá-lo "amador", no sentido pejorativo do termo: o produto fornecido por eles tem a qualidade desejada pelas emissoras e avaliada pelos usuários como excelente ou superior à profissional.

Talvez seja por influência dessas equipes que a própria Netflix tenha mudado suas práticas de recrutamento e de parâmetros técnicos: em 2017, a empresa lançou o Hermes ${ }^{14}$, uma plataforma de seleção de tradutores. Qualquer pessoa interessada pode se candidatar e realizar os testes, independente de formação acadêmica ou experiência com legendagem. 0 exame é muito parecido ao da InSUBs, principalmente na etapa prática de traduzir uma cena. Além disso, o candidato deve seguir os parâmetros estabelecidos no Guia de Estilo ${ }^{15}$ da empresa.

É um sinal importante de que a legendagem voluntária possui atributos de inovação e adequação: a prática profissional começa a assimilar essas qualidades e a incorporá-las em seus negócios. Em nossas considerações finais, refletiremos sobre esses atributos e sobre como eles podem contribuir para a formação e o trabalho de tradutores de legendas.

\section{Considerações finais}

Quando analisamos a legendagem voluntária, o que fica claro é que não se trata de um movimento com o intuito de gerar lucros para os legenders: a

\footnotetext{
${ }^{14}$ Disponível em: <https://media.netflix.com/pt_pt/company-blog/netflix-is-looking-for-the-besttranslators-around-the-globe>. Acesso em 18 jul. 2018.

${ }^{15}$ Disponível em: <https://partnerhelp.netflixstudios.com/hc/en-us/articles/215600497-BrazilianPortuguese-Timed-Text-Style-Guide>. Acesso em 18 jul. 2018.
} 
prática é uma união entre o afeto dos fãs pelas séries e a vontade de se conectar a elas, à suas etapas de produção e distribuição e aos outros fãs.

Esse fato demonstra que, diferentemente do trabalho profissional, a lógica desse tipo de trabalho voluntário apoia-se no compartilhamento de bens e de serviços intelectuais: sem o trabalho dos legenders, milhares de pessoas provavelmente não teriam acesso a boa parte dos produtos audiovisuais que consomem. A prática é um exponente importante dos movimentos colaborativos presentes na rede e chama a atenção para um novo olhar sobre as fronteiras entre o mundo real e a internet e os conceitos conservadores que possuímos sobre propriedade.

Em uma análise ampla, é possível reconhecer diferenças marcantes entre $o$ trabalho profissional e o voluntário: enquanto a legendagem profissional é descrita, pelos próprios tradutores, como um trabalho invisível e sem retorno crítico, a prática legender conta com o envolvimento da comunidade que consome diretamente seus produtos. Além disso, enquanto a legenda profissional não deixa claros quais são seus critérios técnicos, a voluntária segue, de forma mais consistente, os padrões estabelecidos por quem as publica.

Algumas das estratégias empregadas na organização de trabalho dos legenders, analisadas neste estudo, podem trazer contribuições interessantes para o treinamento de tradutores no contexto acadêmico. A primeira delas estaria no próprio aprendizado de trabalho em equipe, com divisões específicas de tarefas, promovendo um ambiente de tradução mais dinâmico, especialmente com a designação de um revisor responsável pela padronização dos termos e da verificação dos parâmetros técnicos. Uma vez que várias pessoas traduzem trechos diferentes de um mesmo episódio (assim como é comum equipes de tradutores traduzirem trechos de um mesmo texto), termos recorrentes podem aparecer traduzidos de formas diferentes pelos tradutores responsáveis. Além de ferramentas adotadas para padronizar as traduções (como sistemas de memória, por exemplo), a designação de um revisor pode servir para uniformizar as traduções, analisar as diferentes 
opções fornecidas por tradutores, permitindo a definição do termo mais adequado e a padronização integral do texto.

O estabelecimento de parâmetros técnicos também é um fator a ser considerado na formação de legendistas: a preocupação das equipes com esses limites e seu sucesso no produto final mostram que o telespectador demanda tempo hábil para ler as legendas sem que elas “pisquem” na tela, além de preferir legendas mais curtas e sintetizadas, mas que não reduzam completamente elementos necessários para a compreensão da cena.

A organização estrutural da equipe, por meio de um sistema interno com ferramentas integradas, é também muito útil ao seu sucesso: a padronização e a comunicação que discutimos neste estudo não seriam tão dinâmicos sem o emprego de um banco terminológico para cada série, por exemplo. Também seria menos acessível ao tradutor profissional uma avaliação crítica de suas legendas, indicando pontos que precisam melhorar ou que estão dentro das expectativas. Os tutoriais e guias de estilo também são fundamentais, já que não só impõem regras técnicas, mas explicam como (e por quê) elas devem ser aplicadas, quais seus efeitos práticos e por quais razões algumas medidas devem ser evitadas.

Em síntese, o conceito de "equipe" atribuído ao trabalho não se restringe aos membros da equipe ou à comunidade de tradutores: ele se estende aos usuários, às tecnologias disponíveis, à cultura que permeia os produtos e à intimidade com a obra em si. É um serviço com o qual todos ganham: a comunidade de fãs, que tem suas demandas e sugestões atendidas, as obras audiovisuais, que são divulgadas e promovidas pelos próprios consumidores e os legenders, que têm seu trabalho reconhecido e a oportunidade de interagir com as séries pelas quais se interessam. A relação entre esses três elementos sugere que, em um universo de conteúdo disperso e público, em que não parece haver barreiras de propriedade ou valores monetários, o conhecimento também parece exceder valores antigos e se recusar a ser restrito: sua expansão é uma obrigatória consequência da inteligência coletiva que o mundo conectado nos trouxe. 


\section{Referências}

Bernardo, M. H. P. Subtitulando: o universo dos legenders e fansubbers no Brasil. São Paulo, 2011. 114f. Trabalho de Conclusão de Curso (Especialização) - Pós-graduação lato sensu em Comunicação Social, Faculdade Cásper Líbero. Disponível em:

<http://nonameshideout.com/Monografia\%20-\%20Subtitulando.pdf>. Acesso em 14 jul. 17.

Dicionário AUleTE Digital. Disponível em: <http://www.aulete.com.br/>. Acesso em 22 mai. 2018.

Dicio, DicIONÁRIO ONLINE DE PORTUGUÊS. Disponível em: <https://www.dicio.com.br/aurelio-2/>. Acesso em 23 maio 2018.

DoRland, W. A. Dorland's Illustrated Medical Dictionary. 28. Ed. Philadelphia: Sanders, 1994. 1940p

IMDB. Movies, TV and Celebrities. Disponível em: <https://www.imdb.com/>. Acesso em 01 jul. 2018.

INSUBS. Disponível em: <http://www.insubs.com>. Acesso em 01 jul. 2018.

US NATIONAL LiBRARY OF MEDICINE. PubMed.gov. Disponível em: <https://www.ncbi.nlm.nih.gov/pubmed>. Acesso em 01 jul. 2018.

INTERNET LIVE STATS. Disponível em: <http://www.internetlivestats.com/>. Acesso em 29 jun. 2018.

JENKINS, H. Convergence culture: where old and new media collide. New York and London: New York University Press, 2006.

LEGENDAS.TV. Disponível em: <http://www.legendas.tv>. Acesso em 01 jul. 2018.

SPOLIDORIO, S. M. Comunidades Online e Legendas de Fãs: Novas Formas de Produzir e Consumir Legendas. Campinas, 2017. 136f. Dissertação apresentada ao Instituto de Estudos da Linguagem da UNICAMP para obtenção do título de Mestra em Linguística Aplicada, na área de Linguagem e Sociedade. Disponível em: <http://repositorio.unicamp.br/jspui/bitstream/REPOSIP/322463/1/S polidorio_Samira_M.pdf>. Acesso em 01 jul. 2018

Stedman, T. L. Stedman's Medical Dictionary. 27. ed. Rio de Janeiro: Guanabara Joogan, 2003. 2017p. 
Recebido em: 24/07/2018

Aceito em: 28/03/2019

Publicado em maio de 2019 